\title{
The productivity paradox and the diffusion of generic technologies
}

\author{
SANDRINE PAILLARD*
}

\begin{abstract}
The productivity paradox poses the problem of the coexistence, since the seventies, of a slowing down of productivity gains and an acceleration of technical progress, in particular in the field of information technologies (IT). The existence of delays between the arrival of a new technology and the realisation of productivity gains constitutes one explanation of the paradox. In this article, we present a simulation model which illustrates the relations between the diffusion of a generic technology and the dynamics of the productivity gains at the macroeconomic level. In this model, the diffusion of a new generic technology is a process marked by positive feedback; any obstacle to the diffusion also hinders the pace of learning which, in turn, slows down the process of diffusion. A low rate of the diffusion of the knowledge among the sectors of the economy slows the diffusion down. In a similar way, the heterogeneity of the stock of capital and the problems of technological compatibility resulting from it make the full potential of the new technology more difficult to obtain.
\end{abstract}

\section{Introduction}

The productivity paradox, formulated by Solow in 1987, poses the problem of the coexistence in developed countries since the seventies, of a slowing down of productivity gains and an acceleration of technical progress, in particular in the field of information technologies (IT). Several explanations of this phenomenon have been proposed (see Brynjolfsson, 1995; Paillard, 1998 for literature on the paradox). The existence of delays between the arrival of a new technology and the realisation of productivity gains constitutes one explanation of the paradox (David, 1991; Freeman and Perez, 1988; Helpman and Trajtenberg, 1994). Indeed, a technological innovation does not immediately translate into productivity gains. The diffusion and the efficient utilisation of a radical

* Commissariat Général du Plan, 18 rue de Martignac, 75700 Paris 07 SP, France.

E-mail: spaillard@plan.gour.fr

Keywords: Productivity paradox, information technologies, generic technologies, technological learning.

(c) EDP Sciences 2000 
innovation can take time; a process of experimentation from the firms, the sectors and the whole economy is necessary to obtain economic benefits associated to its adoption (Rosenberg, 1972).

IT are considered as a key factor of a new techno-economical paradigm (Freeman and Perez, 1988) or as a generic technology (Helpman and Trajtenberg, 1994). Whichever concept is adopted, these technologies are characterised by their pervasiveness, they can be used and incorporated into several products and processes of production in all the economy, and by their dynamism, they are subjected to continuous and fast technological improvements (Bresnahan and Trajtenberg, 1992). These two main features of generic technologies tend to lengthen the period of experimentation. Indeed, pervasiveness and dynamism tend to hinder the processes of learning and technological standardisation which are necessary to improve diffusion and user's performances.

In this article, we present a simulation model which illustrates the relations between the diffusion of a generic technology and the dynamics of the productivity gains at the macroeconomic level. The realisation of learning and standardisation processes determines the productivity gains achieved by sectors using the technology, which, in turn, influence the pace of diffusion. We present the structure of the model in a first section. Then, in the second section, we show the results of the model simulations.

\section{The structure of the model}

The model describes the transition between two techno-economic paradigms in an economy composed of several sectors of production. One sector produces equipment and several sectors use this equipment in order to produce consumer goods. Each sector of production is composed of a representative firm. We suppose therefore that the diffusion and the realisation of productivity gains within a representative firm correctly describe the same processes at the sector level. As a consequence, we neglect the competition between firms although the latter influences the process of technological diffusion.

Each paradigm is embodied into a production technology. The technology related to the current paradigm reaches the end of its technological trajectory; it is distributed in the whole economy. The new paradigm corresponds to a technology which is not initially distributed.

In order to take into account the pervasiveness of generic technologies, we suppose that the introduction of the new paradigm into economy is progressive. The sectors of production of different consumer goods will not necessarily adopt (if they do) the new technology at the same time. The radical innovations corresponding to successive generations of the technology make it possible to progressively widen the field of possible applications.

The sectors producing consumer goods innovate by buying new equipment in order to extend their production capacity and to replace their obsolete equipment. The stock of capital of each representative firm can therefore be composed of both technologies as well as the different generations of a same technology. Thus, the unit cost of production is determined by the structure of capital stock. The equipment which is characteristic of the old paradigm is used at its full potential in terms of productivity since it has been 
known and used for a long time by the firms. Besides, we suppose that the equipment which characterises the old paradigm belongs to the same generation. However, the firms must learn how to use the equipment belonging to the new paradigm. Following the steps of Silverberg, Dosi and Orsenigo (1988) and of Chiaromonte and Dosi (1992), we suppose that each firm holds a specific rate of competence in the utilisation of new technology, so that the effective labour productivity is inferior to the potential productivity. The competence of the firms improves, thanks to a learning process and an externality allowing each sector to take advantage of the experiences of others.

The overall performance of each firm in terms of labour productivity depends not only on the productivity realised with each type of equipment but also on the "coherence" of the stock of equipment of the firm. As a consequence, the productivity of each firm is weighted by a heterogeneity coefficient, depending on the "technological distance" between the oldest and newest generations used and on the dispersion of the stock between different generations. The more technologically distant items of equipment are, the more the stock is dispersed between a great number of different generations, and the less efficient the firm will overall be.

\subsection{The demand for consumer goods}

The economy is composed of $m+1$ sectors. One sector $(j=0)$ produces heterogeneous equipment goods with labour as input. $m$ sectors $(j=1 \ldots m)$ produce consumer goods with equipment and labour. One unit of capital makes it possible to produce one item of good. Each sector producing consumer goods is composed of a representative firm which produces one homogeneous good ${ }^{1}$.

Labour supply is exogenous and unlimited and labour is homogeneous. The wage rate evolves with the productivity gains in the whole economy ${ }^{2}$ :

$$
w(t)=w(t-1)\left(1+\gamma \frac{a(t-1)-a(t-2)}{a(t-2)}\right) \quad 0 \leq \gamma \leq 1
$$

$\gamma$ is a parameter translating the degree of indexation of wages to the productivity gains, $w(t)$ describes the wage rate and $a(t)$ is the aggregated productivity.

Prices of the goods are defined by a mark up rate on the average labour costs:

$$
p^{j}(t)=\left(1+\alpha^{j}\right)\left(\frac{w(t)}{a^{j}(t)}\right) \quad 0 \leq \alpha^{j}<1
$$

where $a^{j}$ is the average labour productivity in sector $j$ and $\alpha^{j}$ its mark up rate.

\footnotetext{
${ }^{1}$ See Nelson and Winter (1982), Silverberg, Dosi and Orsenig (1988) and Chiaromonte and Dosi (1992) for an analysis of the relation between diffusion of innovations and competition in sector based and macroeconomic models.

${ }^{2}$ More precisely, the wage rate evolves with the productivity gains aggregated in the sectors producing the consumer goods.
} 
Households have a rigid consumption structure; they dedicate a constant fraction of their budget to the purchase of goods of each type. The total consumption budget increases at a constant rate:

$$
p^{j}(t) D^{j}(t)=d^{j} B(t) \quad \forall t, \forall j \neq 0,0<d^{j}<1
$$

where $D^{j}$ is the demand in volume addressed to sector $j, d^{j}$ is the share of the consumers' budget dedicated to the good $j$ and $B$ the total budget of households. There can be rationing of goods $j(j \neq 0)$ if sector $j$ has underestimated, in volume, the demand it would get.

\subsection{The technological opportunities}

The model describes the transition between two techno-economic paradigms. The generic technology relative to the current paradigm is noted $O$ and the emerging paradigm is noted $N$. Incremental innovations improve both technologies during each period. Moreover, the new paradigm benefits from radical innovations. For clarity's sake, we use the terms "vintage" for incremental innovations and "generations" for radical innovations. The incremental innovations reflect the dynamism of generic technologies and correspond to an increase of the productivity potential of each technology. The radical innovations which reflect the pervasiveness of generic technologies only occur at certain periods and correspond to successive generations of the new technology. They are not defined in terms of progress of productivity but allow an extension of application opportunities to an additional sector.

Generations of the new paradigm $(i=1$ to $n)$ are introduced in an exogenous way during certain periods of production. The periods of production are noted $t$ and the periods of arrival of a new generation of equipment are noted $t_{i}^{*}, i=1 \ldots n$. At time $t_{i}^{*}$, the sectors $j, j=1, \ldots i-1, i$ are the potential users of the $i$ th generation of the new technology. In other words, the sector producing the consumer goods 1 is the only one which can potentially adopt the first generation of the new technology. The second generation will concern the first and second sectors $(j=1,2)$ and so on, until we reach generation $m$ which will be usable by all sectors of consumer goods ${ }^{3}$.

During each period, the sector of equipment goods produces and offers a new vintage of each technology, allowing users to reach a potential labour productivity superior to the precedent vintage. The potential of productivity of each technology increases at a constant rate:

$$
A_{i}(\tau)=A_{i}(\tau-1)\left(1+\delta_{i}\right) \quad i=O, N
$$

where $A_{i}(\tau)$ is the potential labour productivity for the sectors using vintage $\tau$ of technology $i$ and $\delta_{i}$ the growth rate of the potential of technology $i$. The potential of the new technology for the sectors using it is always superior to the potential of the old one.

$$
A_{O}(\tau)<A_{N}(\tau) \quad \forall \tau
$$

${ }^{3} m \leq n$. 
The sector making equipment produces what the using sectors order. Each year, it produces and offers only the new vintage of each technology. The prices of the equipment are equal to the unit cost of production. The cost of production of the equipment decreases as a result of the experience gained in the production within each paradigm.

$$
p_{i}^{K}(\tau, t)=\frac{w(t)}{m_{i}\left[x_{i}(t-1)\right]^{\beta_{i}}} \quad 0 \leq \beta_{i}<1 \quad i=O, N
$$

where $p_{i}^{K}(\tau, t)$ is the price at time $t$ of the vintage $\tau$ of equipment belonging to techno$\log i, m_{i}$ is the initial labour productivity in this technology, $x_{i}$ is the cumulated production using technology $i$ and $\beta_{i}$ is the associated coefficient of learning 4

$$
x_{i}(t)=\sum_{\tau=0} K_{i}^{0}(\tau) \quad i=O, N
$$

where $K_{i}^{0}(\tau)$ is the amount of equipment from vintage $\tau$ belonging to technology $i$ produced and sold in $t=\tau$.

\subsection{The dynamics of productivity gains}

In the firm, the effective labour productivity relative to a vintage can be different from potential productivity as the result of, first, a learning process, and second, the heterogeneity of the stock of capital which affects the overall efficiency.

The technology characterising the old paradigm, being known by the firms for long, is used at its full potential. However, the potential of the new technology is weighted by a skill rate which is specific to each firm. This private skill rate, noted $s^{J}$, evolves with the experience gained in the firm using the new technology. We suppose, following Silverberg, Dosi and Orsenigo (1988), that the learning process follows a logistic trajectory.

$$
\begin{aligned}
& s^{j}(t)-s^{j}(t-1)=\phi\left[\frac{Q_{N}^{j}(t-1)}{P C_{N}^{j}(t-1)+C}\right] s^{j}(t-1)\left[1-s^{j}(t-1)\right] \quad 0<\phi<1 \\
& \text { if } s^{j}(t)>s^{p}(t) \quad ; \quad s^{j}(t)=s^{p}(t) \quad \text { if not }
\end{aligned}
$$

where $\phi$ is a parameter reflecting the pace of learning process, $C$ is a constant, $Q_{N}^{j}(t)$ is the current production with the new technology and $P C_{N}^{j}(t)$ is the cumulated production with the new technology (knowing that one unit of capital makes it possible to produce one item of good). The private competence has a tendency to circulate within the whole economy via a learning externality. This externality allows all the firms (whether they have or not experience in producing with the new technology) to benefit from a rate of public skill $s^{p}(t)$, which corresponds to the rate of competence available in the economy without experience being necessary.

\footnotetext{
${ }^{4}$ The sector of equipment goods only produces in $t$ the most modern vintage of each technology. As a consequence $p_{i}^{K}(\tau, t)=p_{i}^{K}(t)$.
} 
The rate of public skill is initially (on the date when the new technology was introduced in the economy) equal to a parameter $\varphi$ corresponding to the level of competence reached, thanks to the information or "instructions" supplied with the equipment. The rate of public skill increases with the diffusion of technology via the learning externality.

$$
\begin{aligned}
& s^{p}(t)-s^{p}\left(t-{ }_{n} 1\right)=\sigma\left[\bar{s}(t-1)-s^{p}(t-1)\right] \quad 0 \leq \sigma \leq 1 \\
& \bar{s}(t-1)=\sum_{j=1} d^{j} s^{j}(t-1)
\end{aligned}
$$

$\bar{s}(t)$ is the average rate of public skill, $\sigma$ is a parameter which is all the higher as the appropriability of private competence is low (or as the externality is strong). Thus, the first firm adopting the new technology starts with a competence rate equal to $\varphi$ whereas the following firms will start with a superior skill rate, equal to the public skill rate recorded on the day of adoption.

The content of the stock of capital affects the overall efficiency of the firm. The heterogeneity of the stock of capital has, indeed, a tendency to diminish the efficiency of the firm because of the technical and organisational difficulties it leads to. The firm's productivity is thus weighted by a heterogeneity coefficient equal to 1 when the stock is perfectly homogeneous (that is when it is composed of only one generation of equipment) and it decreases when the heterogeneity increases. This coefficient $h^{j}(t)$ depends, at once, on the technological distance between the different types of equipment composing the stock of capital of the firm and on the dispersion of the stock. The heterogeneity coefficient is all the higher as the number of existing generations (adopted effectively or not by the firm) between the oldest and the most modern equipment of the stock is large. Thus, scrapping the oldest equipment tends to improve the overall efficiency of the firm. Besides, the bigger the number of different generations the stock is dispersed into, the higher the coefficient of heterogeneity will be. Thus, as far as the firm's overall efficiency is concerned, a stock which is homogeneous in its composition per generation is preferable to a fragmented stock, composed of small quantities of several technological generations.

$$
h^{j}(t)=\left[\left[\max i^{j}(t)-\min i^{j}(t)+1\right]^{-1} \sum_{i=0}^{n}\left[\frac{K_{i}^{j}(t)}{K^{j}(t)}\right]^{2}\right]^{\eta} \quad i=0, \ldots n
$$

$\max i^{j}$ and $\min i^{j}$ are respectively the most modern and the oldest generations of equipment of firm $j$ in $t$ and $\eta$ is a parameter reflecting the impact of heterogeneity on the overall productivity of the firm 5 .

In short, the effective productivity of a vintage is defined as the product of its potential, of the skill rate reached by the firm with the technology which the vintage belongs to and of the coefficient of heterogeneity.

$$
a_{i}^{j}(\tau, t)=h^{j}(t) A_{i}(\tau) s^{j}(t) \quad i=O, N
$$

with $s^{j}$ equals to one when the vintage belongs to the old paradigm.

\footnotetext{
${ }^{5}$ Here, the equipment belonging to the old paradigm corresponds to a generation (whose index is 0 ) so that one can take into consideration the loss of efficiency resulting from the coexistence of both paradigms in a firm.
} 
The average productivity of the sector is the sum of the coefficients of productivity associated to each vintage, weighted by their importance in the total production of the sector.

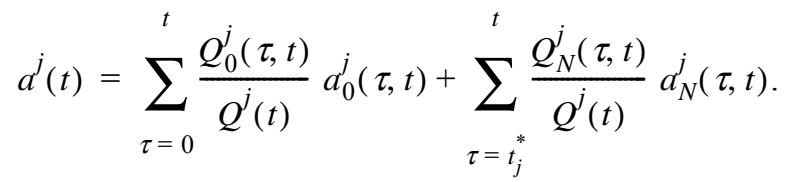

Lastly, the aggregated labour productivity in the economy is the sum of the productivity in each sector weighted by the share of each sector in the aggregated production.

$$
a(t)=\sum_{j=1}^{n} \frac{Q^{j}(t)}{Q(t)} a^{j}(t)
$$

\subsection{The production and investment decisions}

Every time a period of production starts, the representative firm in each sector decides on its investments for the period. We suppose that it is not limited by its financial possibilities. The investment decision consists of choosing the volume of investment and the technology to purchase.

The firm can, at once, widen its production capacity and replace the oldest equipment of its stock. The firm wishes to widen its production capacity if the amount of goods it now wishes to produce and market exceeds the production capacity inherited from the previous period. The level of current production is derived from adaptative anticipations of the demand. The anticipations are calculated from the growth rates of anticipated and effective demands received by the sector during the previous two periods.

$\tilde{D}^{j}(t)=\tilde{D}^{j}(t-1)\left[1+\mu \frac{\tilde{D}^{j}(t-1)-\tilde{D}^{j}(t-2)}{\tilde{D}^{j}(t-2)}+(1-\mu) \frac{D^{j}(t-1)-D^{j}(t-2)}{D^{j}(t-2)}\right] \quad 0 \leq \mu \leq 1$

where $\mu$ is a parameter. If the firm anticipates that the demand will be inferior to its existing production capacities, it will not make expansion investments and will use the most efficient equipment of its stock.

Given the capital stock and the unsold goods of the previous period, the determination of the total investment is automatic:

$$
I E^{d j}(t)=\max \left(0, \tilde{D}^{j}(t)-K^{j}(t-1)-S^{j}(t-1)\right)
$$

where $I E^{d j}(t)$ is the expansion investment of the firm $j, \tilde{D}^{j}(t)$ the demand it anticipates for the period, and $K^{j}(t-1)$ and $S^{j}(t-1)$ are respectively the stock of capital and stock of goods unsold during the previous period.

Besides, the firm can scrap one part of its equipment and replace it with more modern equipment. In this case, the oldest equipment is replaced by the vintage available in $t$ of the technology chosen for expansion investment.

The investment decision is founded on the payback period criteria. For each period, firms have the choice between the two current vintages of the two technologies. The new technology is preferred to the older if it is cheaper for each acquired unit of capacity, or 
if the difference in terms of prices between both technologies can be recovered in a number of periods inferior or equal to the payback period of the firm by reducing the labour cost. Again, following Silverberg, Dosi and Orsenigo (1988), we suppose that the firms anticipate the pace at which their ability to use the new technology is going to improve. As a consequence, in the payback period criteria, the costs of labour - in the case where the new technology is used - are weighted by an "anticipation bonus", reflecting the optimism of the firm as for the speed at which the efficiency of use of the new technology is going to improve. The firm knows that it will not initially use the new technology to its full potential of productivity but it knows that its experience with the new technology will allow them to reach it.

As for the expansion investment, therefore, the new technology will be preferred to the older if:

$$
p_{N}^{K}(t)-p_{O}^{K}(t) \leq b^{j}\left(\frac{w(t)}{A_{O}(t)}-\frac{w(t)}{s^{j}(t) A_{N}(t) \theta^{j}}\right)
$$

where $\theta^{j}$ is a parameter corresponding to the anticipation bonus of the firm and $b^{j}$ is the payback period of the firm.

The firm decides to replace the oldest vintages $\tau$ of its stock (by the technology chosen for expansion), if the price of the new equipment is recovered by reducing the cost of labour in a number of periods inferior to its payback period.

$$
p_{i}^{K}(t) \leq b^{j}\left(\frac{w(t)}{a_{i}^{j}(\tau, t)}-\frac{w(t)}{a_{i}^{j}(t, t)}\right) \quad i=O, N
$$

Note that the criteria of replacement is more restricting than the criteria of expansion investment. Indeed, it is the effective productivity of the vintage that might replace the oldest vintage of the stock of capital, which is taken into consideration, and not the productivity weighted by the anticipation bonus. We suppose that the firm decides to replace equipment if it is sure of reducing its costs within a number of periods which would be equal to its payback period.

If the desired expansion investment is nil, the firm replaces its old equipment by the technology which minimises the recovering time (if the minimum thus determined remains inferior to its recovering time). 
At the beginning of each period, the firm does not know the heterogeneity coefficient which will be effectively observed as it has not made its investments for the period. We suppose therefore, that the firm weights the productivity coefficients relative to each used vintage with the heterogeneity coefficient observed during the previous period.

\section{The simulations}

In all simulations, the economy is composed of 5 sectors of consumer goods. Sectors are identical in terms of the variables' initial value and the parameters' value. The initial values were calculated so that the economy keeps a steady state, until the new paradigm is introduced. To obtain the steady state, we made the following hypotheses:

1. The rate of nominal wage is perfectly indexed to the productivity gains $(\gamma=1)$;

2. Each sector replaces a whole vintage of its stock of capital (initially composed of ten vintages) at each period;

3. The investment expenses of a firm at each period are equal to its profit for the period.

As a consequence, productivity at the macroeconomic and sector levels increases at the same constant rate until the new technology is introduced.

The potential productivity of the new technology is $80 \%$ superior to that of the pre-existing technology $\left(A_{N}=1.8 A_{O}\right)$. The productivity of both technologies, from one vintage to the other, increases at the same rate (equal to $2.5 \%)\left(\delta_{O}=\delta_{N}=0.025\right)$. The overall demand increases by $5 \%$ during each period. When it is first introduced in the economy, the new technology is used at $35 \%$ of its potential of productivity $(\varphi=0.35)$. The new paradigm is introduced during the 10th period. At this date, only sector 1 is likely to adopt the new technology. Afterwards, a generation of a new technology appears every 8 periods and offers application opportunities to sectors 2 to 5 successively. The new technology is composed of 5 generations of equipment.

Simulation 0 reproduces the dynamics of the economy without the introduction of a new technological paradigm, that is the steady state of the old paradigm. In simulation 1 , parameter $\phi$, which represents the pace of learning, is considered equal to 0.7 ; parameter $\sigma$, which reflects the extent of the externalities of learning, is equal to 0.1 . We do not take into consideration, in this simulation, the effect of the heterogeneity of the stock of capital on the labour productivity $(\eta=0)$.

The evolution of the aggregated productivity (expressed in logarithm) is represented in Figure 1. The dotted line represents the evolution of the level of productivity in simulation 0 (that is without the introduction of a new paradigm).

The introduction of the new technology results in the productivity gains slowing down. About fifty periods after the introduction of the new technology, the economy catches up with and passes the productivity of the steady state characterising the old paradigm. The same time is necessary for the total diffusion of the new technology in the economy (the production of the consumer goods is made with the new technology), (Fig. 2) ${ }^{6}$.

\footnotetext{
${ }^{6} \mathrm{NB}$ : The various graphs do not systematically represent the same number of periods.
} 

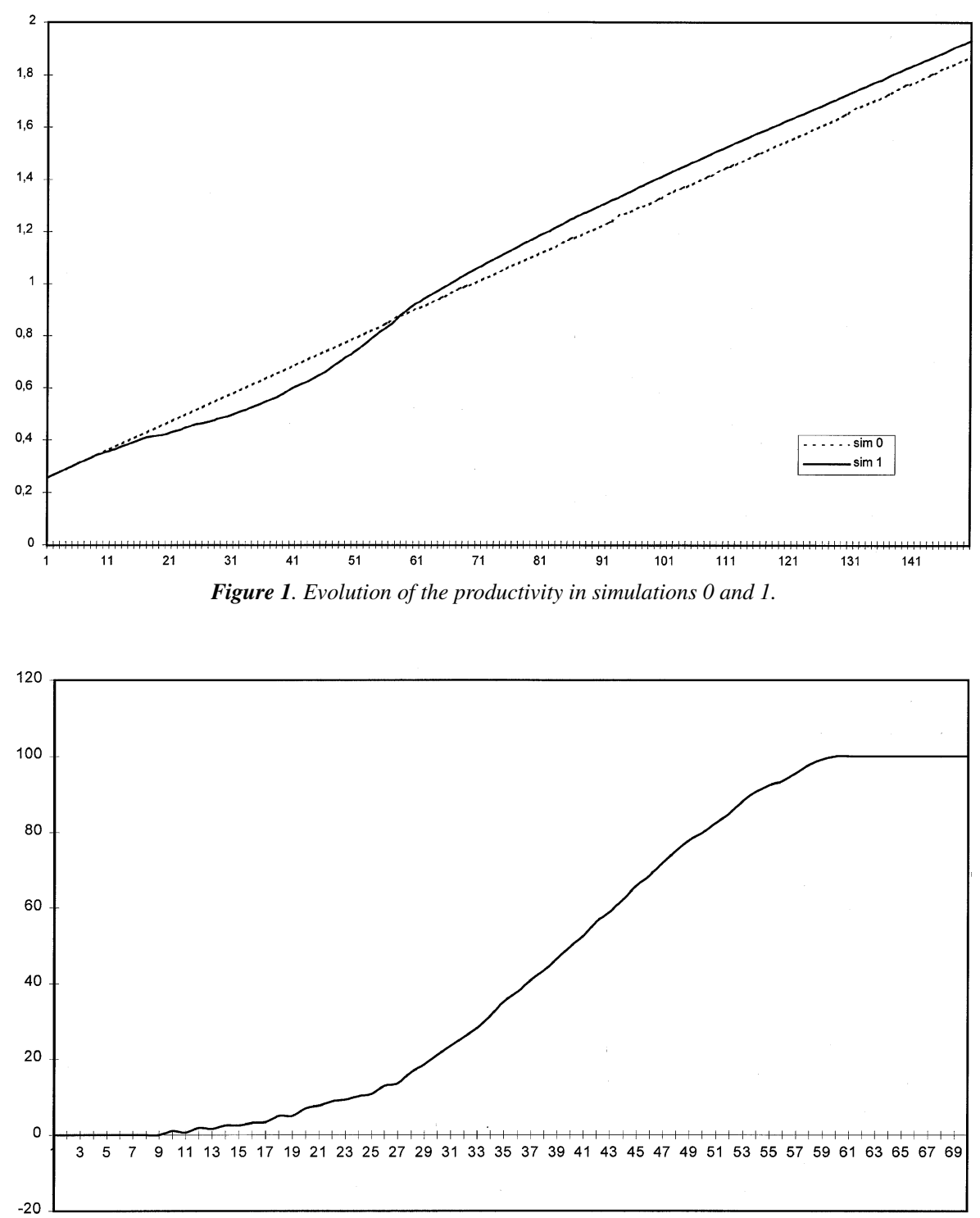

Figure 2. Aggregate diffusion in simulation 1.

\subsection{The effects of technological externalities}

The effects of technological externalities on the diffusion and the dynamics of the productivity can be seen by comparing simulations 2 and 3 of the model. The parameters are identical to those of simulation 1, except for parameter $\sigma$ reflecting the extent of the technological externality. In the second simulation, there is no learning externality $(\sigma=0)$. 


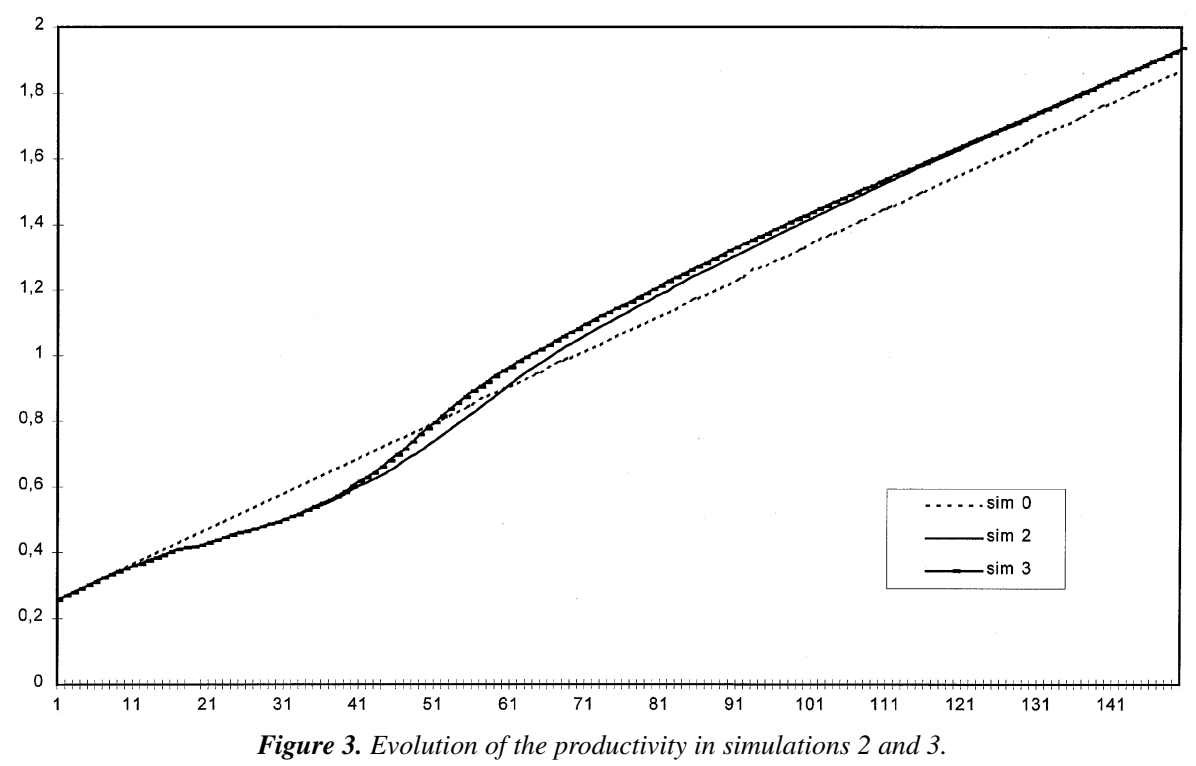

All the sectors start using the new technology with an identical skill rate equal to $35 \%$ of its potential. In the third simulation, the technological externality is maximum $(\sigma=1)$; the firms start using the new technology with a skill rate which is equal to the average of competence accumulated in the economy.

The slowing down of productivity lasts longer in the absence of externality (Fig. 3). The economy needs all the more time to get back to the growth rate of the productivity characterising the steady state as the externality is low. The technological externality allows the firms to learn more quickly how to use the new technology, so that the average level of competence in the economy improves more quickly (Fig. 4). As a consequence, the productivity increases all the quicker as the externality is important, ceteris paribus. In a similar way, the diffusion is all the quicker as the externality is strong (Fig. 5). The more the individual competence circulates, the higher the effective productivity of the new technology. As a consequence, the replacement of the old technology is done more quickly.

However, the extent of the slowing down of productivity gains is only slightly superior in the absence of technological externality in comparison with the case where the externality is maximum ${ }^{7}$. The absence of significant difference between the extent of the slowing down of productivity gains in both simulations can be explained by two types of mechanisms. The first plays on the pace of replacement of the new technology, whereas the second influences the expansion investment.

The replacement of the old technology, at the macroeconomic level, is all the faster as the technological externality is strong. However, the acceleration of the replacement

\footnotetext{
${ }^{7}$ In simulations 2 and 3, the difference to the steady state reaches $18.8 \%$ and $18.5 \%$ respectively.
} 

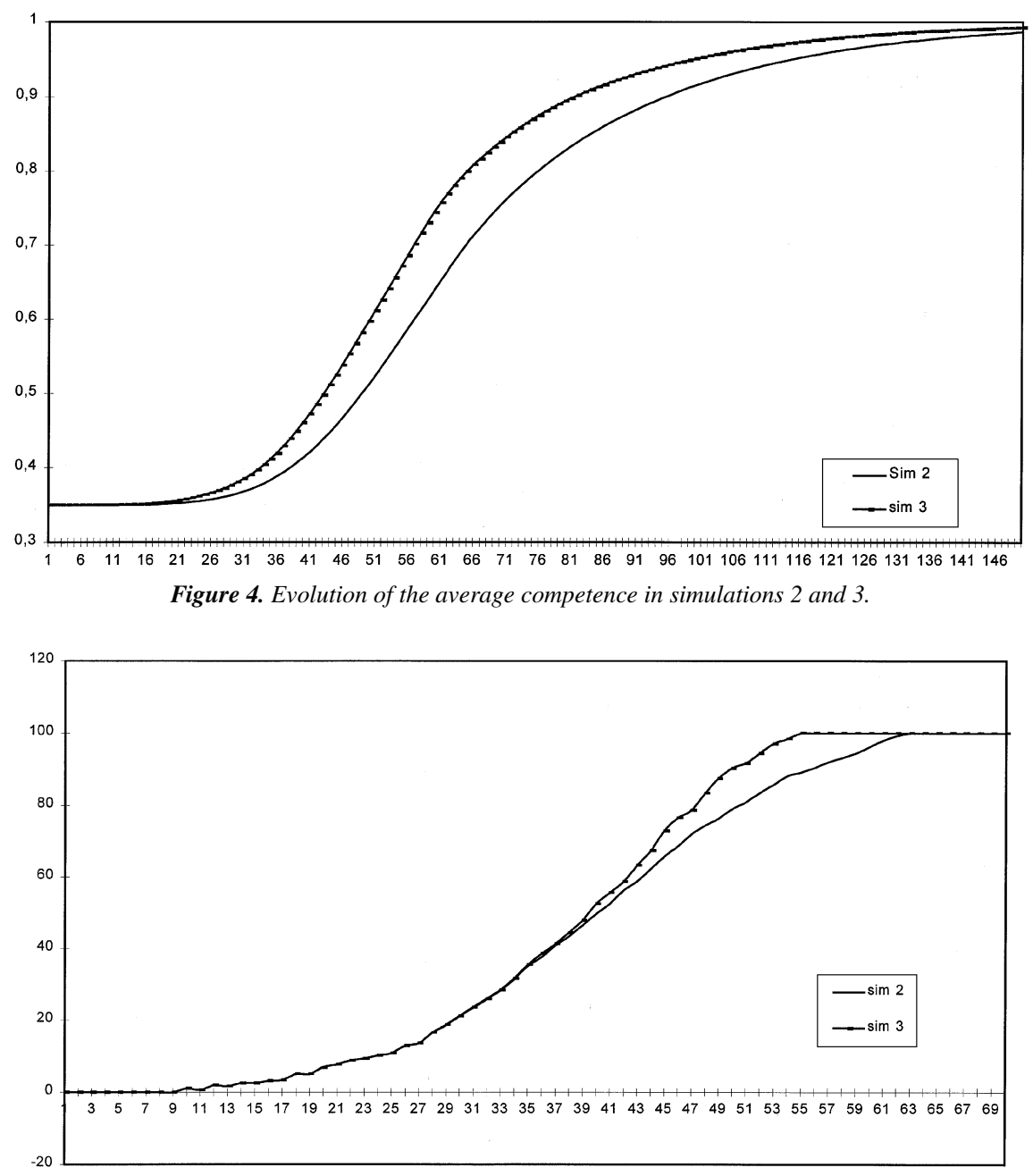

Figure 5. Aggregate diffusion in simulations 2 and 3 .

in simulation 3 compared to simulation 2 is not identical from one sector to the other. Figure 6 represents diffusion within sectors in both simulations. Replacement of the old technology in one sector leads to an acceleration of the diffusion. The beginning of the replacement is therefore noted with an "inflection point" on the curve of diffusion in each sector. Figure 6 shows that the date at which the replacement started does not change from one simulation to another for the first two sectors ${ }^{8}$. However, the replacement of the old technology starts 2,5 and 8 periods respectively more rapidly in sectors 3 ,

\footnotetext{
${ }^{8}$ In fact, the acceleration of replacement rate in simulation 3, compared to simulation 2, only starts, for the first two sectors, at the end of the diffusion and corresponds therefore to a quicker replacement of the vintages of the new technology.
} 


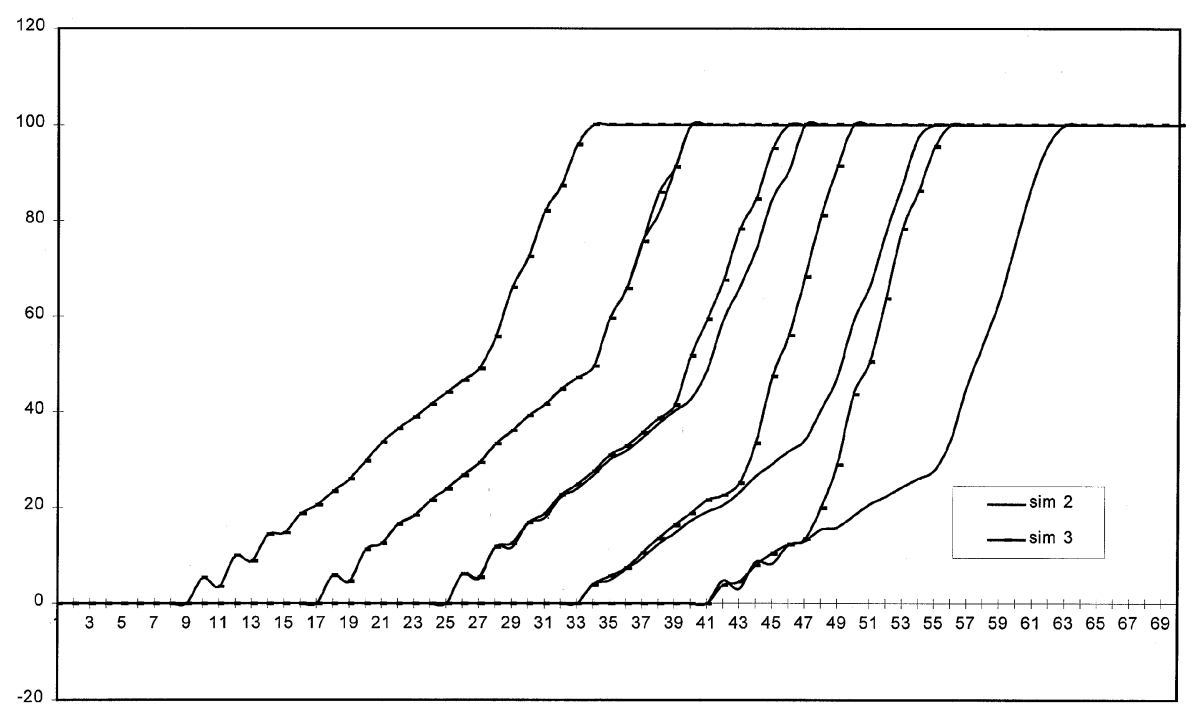

Figure 6. Diffusion at the sector level in simulations 2 and 3.

4 and 5 in presence of externality. This sector based profile of the diffusion can be explained, thanks to the learning process. Indeed, on the one hand, whatever the extent of the externality, sector 1 does not benefit from it since it is the first sector to adopt the new technology. On the other hand, sector 2 benefits from the competence accumulated by the first one, just as the latter is in its first phase of learning during which the improvement of competence is very slow. As a consequence, and as far as sector 2 is concerned, a larger externality has only a small effect on the effective productivity and therefore on the decision to invest. If the interval separating the adoption of the new technology by sectors 1 and 2 had been bigger, sector 2 would have taken more advantage of the externality. Thus, the later the sectors adopt the new paradigm, the more profitable the learning externality will be for them, since they benefit from it when the sectors that preceded them in the adoption are more advanced in their learning process.

We could also have expected the expansion investment in each sector to be superior - in the case of maximum externality - during the period when the sector's productivity gains accelerated. Thus, the diffusion would have been faster and the slowing down of productivity gains less significant in the presence of an externality in each sector. However, as in the case of replacement investment, the externality's influence is all the smaller as the sectors adopt the new technology early. In brief, the beneficial effects of the externality would have been a lot bigger if all the sectors had adopted the new technology at the same time.

\subsection{The effects of the learning pace}

The effects of the learning pace are explored in simulations 4 and 5. In these two simulations the parameters are identical to the ones in simulation 1, except for the parameter 


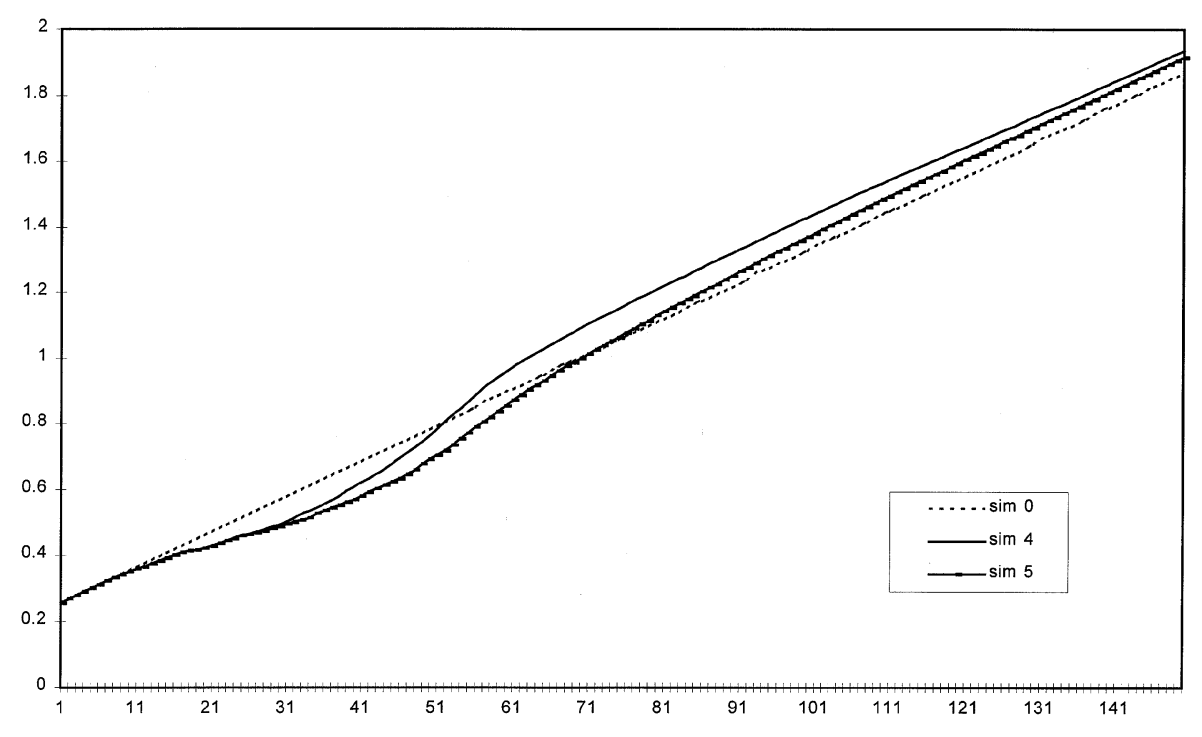

Figure 7. Evolution of the productivity in simulations 4 and 5.

reflecting the learning pace $(\phi)$. In simulation 4 , this parameter is equal to 0.9 , reflecting a fast learning process in comparison with simulation 5 in which it is equal to 0.5 .

The slowing down of productivity gains is at once more prolonged and deeper when the learning takes longer (Fig. 7). However, the respective dynamics of the productivity gains only differ significantly after twenty periods following the introduction of the new technology.

The lengthier slowing down of productivity gains in simulation 5 results directly from a slower improvement of the skill rate (Fig. 8). The influence of the learning pace is equally indirect throughout the process of diffusion. The aggregated diffusion of the new paradigm is slowed down by the effect of an inferior level of competence on decisions of expansion and replacement investment (Fig. 9). However, the diffusion only gets significantly slower sixteen periods after the introduction of the new paradigm.

Figure 10 represents the diffusion in each sector in both simulations. In the case of a slow learning process, the first phase of diffusion is quicker. However, as soon as the replacement of the old technology starts, the diffusion is slower compared to an economy characterised by a fast learning process. These tendencies are all the more significant as the sector's adoption of the new technology is late.

At the time when a sector adopts the new technology, the demand in volume that it gets is all the more important (relatively to the case of a fast learning) as the number of firms which adopted the technology before it is high. The latter firms, going through a higher slowing down of their productivity, have to increase their prices. As a consequence the demand falls more than in the case where the learning is faster. As a result, the differential in the volumes of demand, and then in the diffusion between simulations 4 and 5, is positive in the last phase of the diffusion and is all the higher as the adoption occurs late. Note that if the interval between the arrival of each generation of the new 


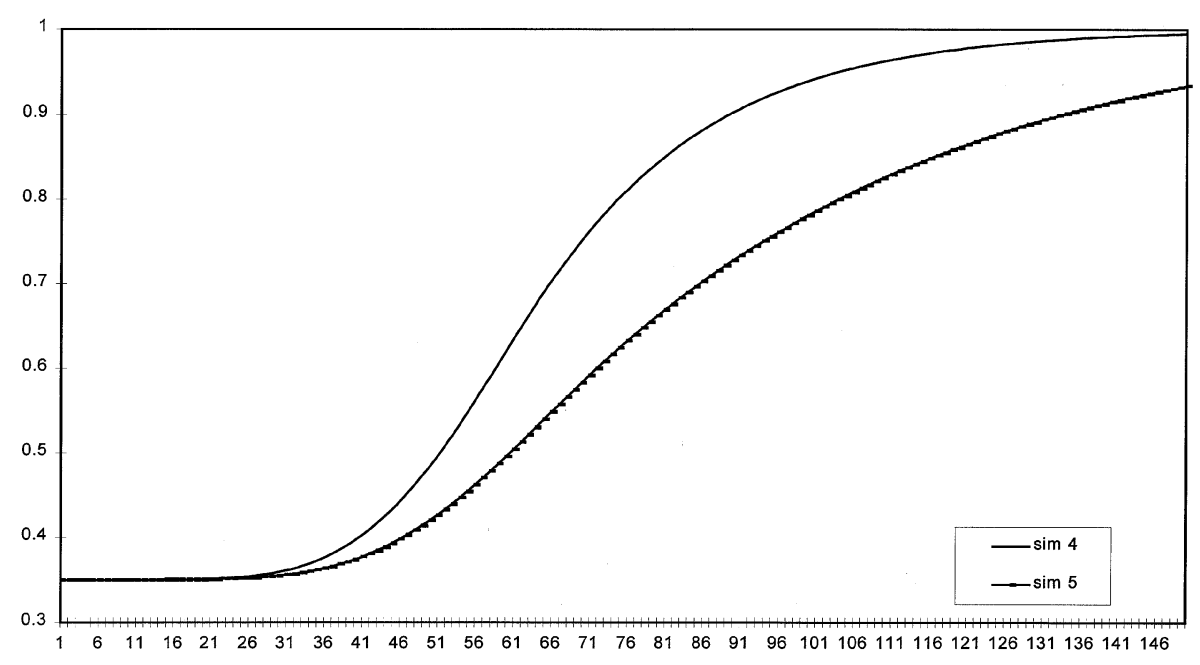

Figure 8. Evolution of the average competence in simulations 4 and 5.

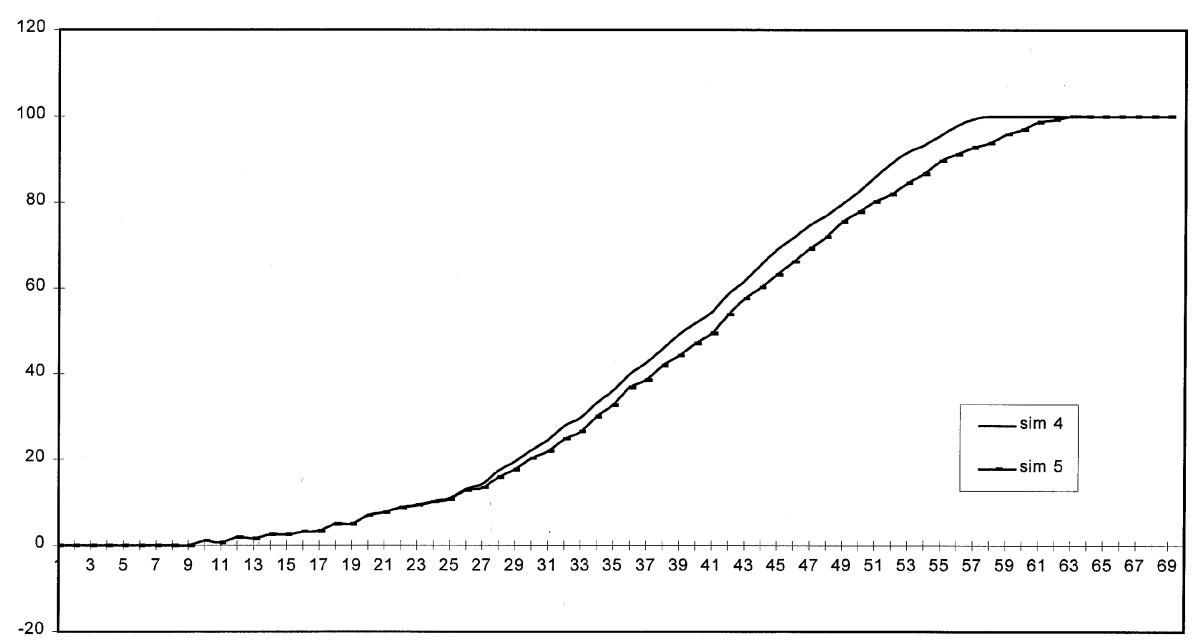

Figure 9. Aggregate diffusion in simulations 4 and 5.

paradigm was superior, the firms adopting the new technology late would not get the same increase in the volume of demand. Indeed, in this case, the firms which adopt late would start to use the new technology at a time when the firms which adopted earlier, are more advanced in their learning process. Thus, the relative prices would be less favourable for the firms which adopted after the others.

The difference of diffusion between both simulations - even though it is all the more significant as the adoption took place late - becomes negative once the sector starts to replace its old equipment by the new technology. The criteria of replacement investment is satisfied later, when the learning is slow, since the effective productivity of each 


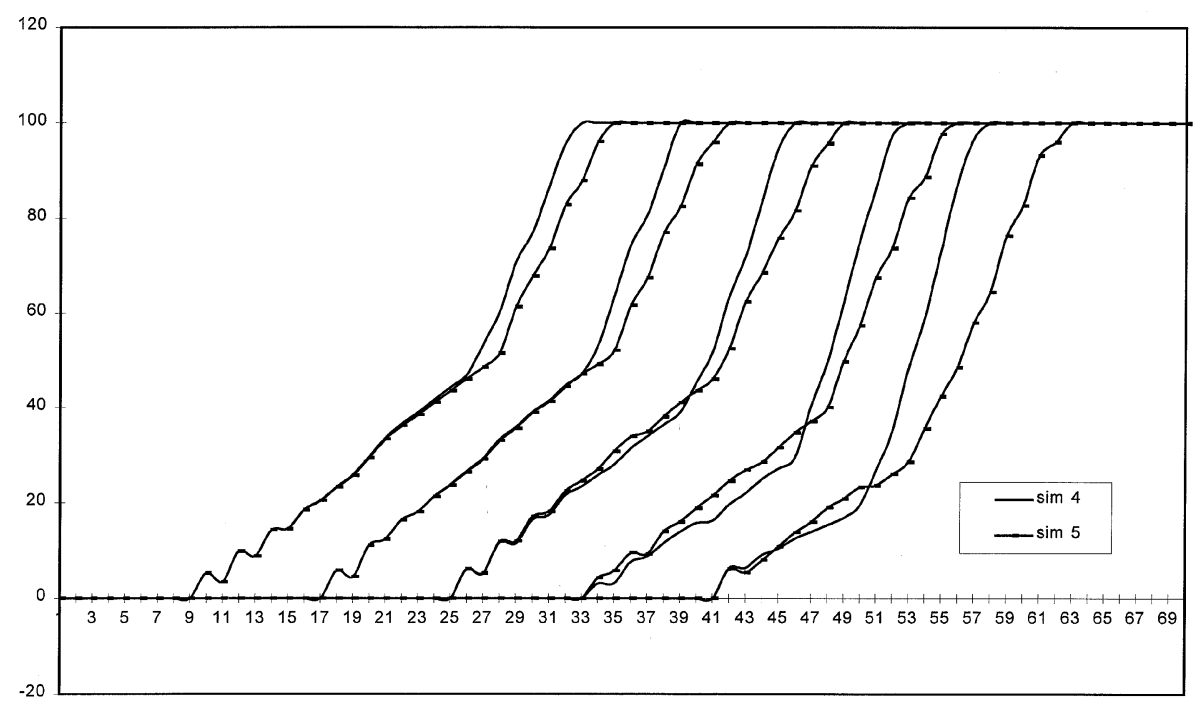

Figure 10. Diffusion at the sector level in simulations 4 and 5.

vintage of the new technology is lower. Indeed, the equipment including the old paradigm is replaced by the new technology later and more slowly. The replacement is all the slower as the sector adopts the new technology late. Indeed, the slower pace of learning affects the level of competence with which a firm uses the new technology through the learning externality. As the level of public skill increases less quickly, the later the firm adopts the new technology, the higher the difference of competence between simulations 4 and 5 will be.

\subsection{The effects of heterogeneity of equipment}

In simulation 6, we consider the effects of heterogeneity of equipment. In this simulation, the average productivity of a firm is weighted by a coefficient of heterogeneity which is equal to 1 when the stock of capital of the firm is perfectly homogeneous, that is when all the equipment it uses belongs to the same generation of a technology. This coefficient decreases, on the one hand, with the technological distance between the oldest and the newest generations of the stock of the firm, and on the other hand, with the dispersion of the stock among different generations of capital. The parameter which reflects the extent of the disadvantage associated to heterogeneity on the average productivity of each firm $(\eta)$ is equal to 0.075 . The other parameters are identical to those in simulation 1 .

Figure 11 represents the evolution of productivity in simulation 0 (steady state), simulation 1 and simulation 6 . The slowing down of the productivity is a lot more significant when the effect of heterogeneity on the productive efficiency of the firms is taken into consideration. The immediate consequence of the coefficient of heterogeneity is to reduce the productivity of the firms as long as the latter use more than one generation of equipment. 

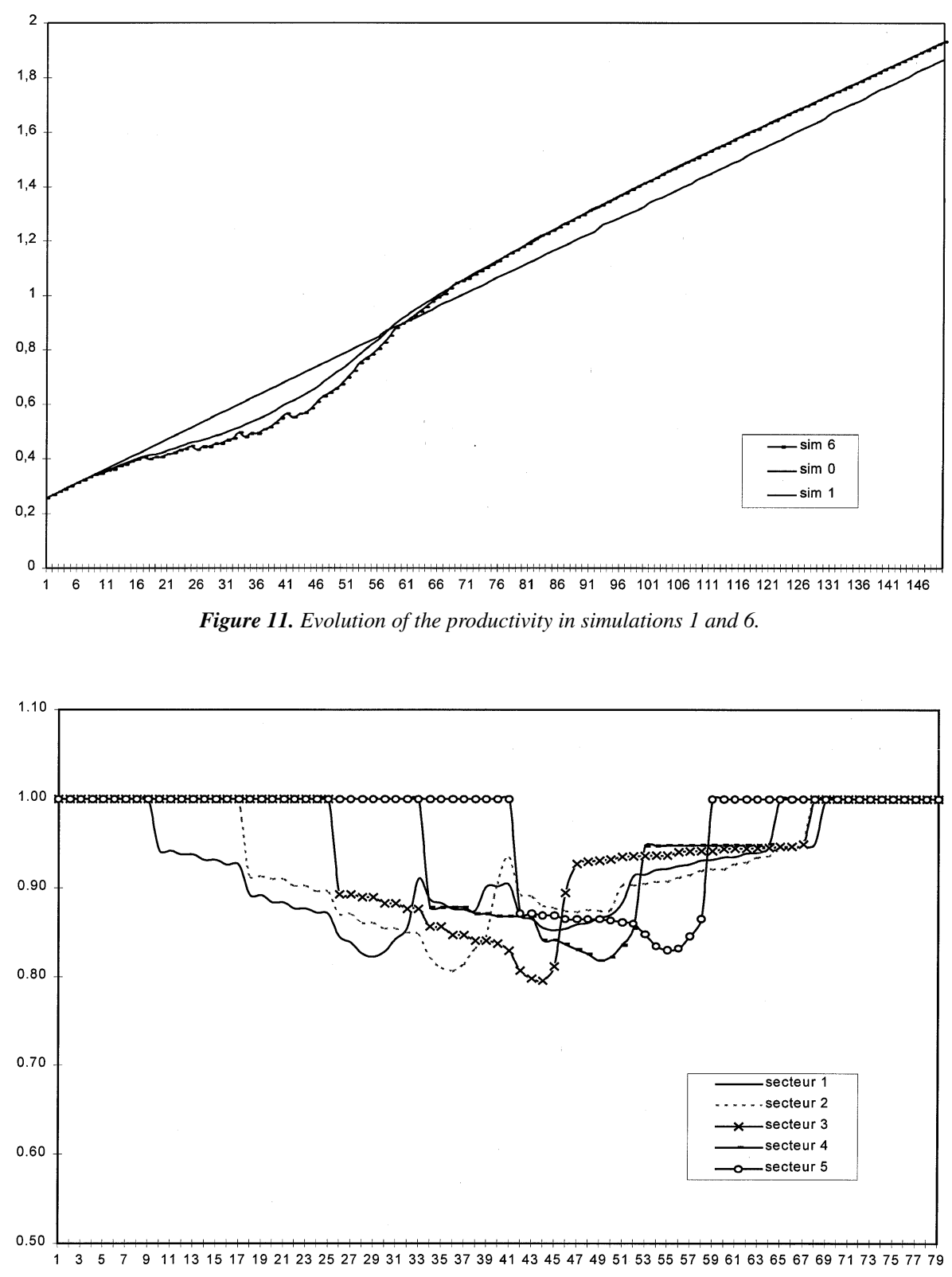

Figure 12. Evolution of heterogeneity coefficients in simulation 6.

The level of aggregated productivity is the lowest during the period when the heterogeneity of the stock of capital affects all the sectors (Fig. 12). The coefficient of heterogeneity reaches different values depending on the sectors. It is maximum in sector 3 . The coefficient of heterogeneity takes account of the distance as well as of the technological 


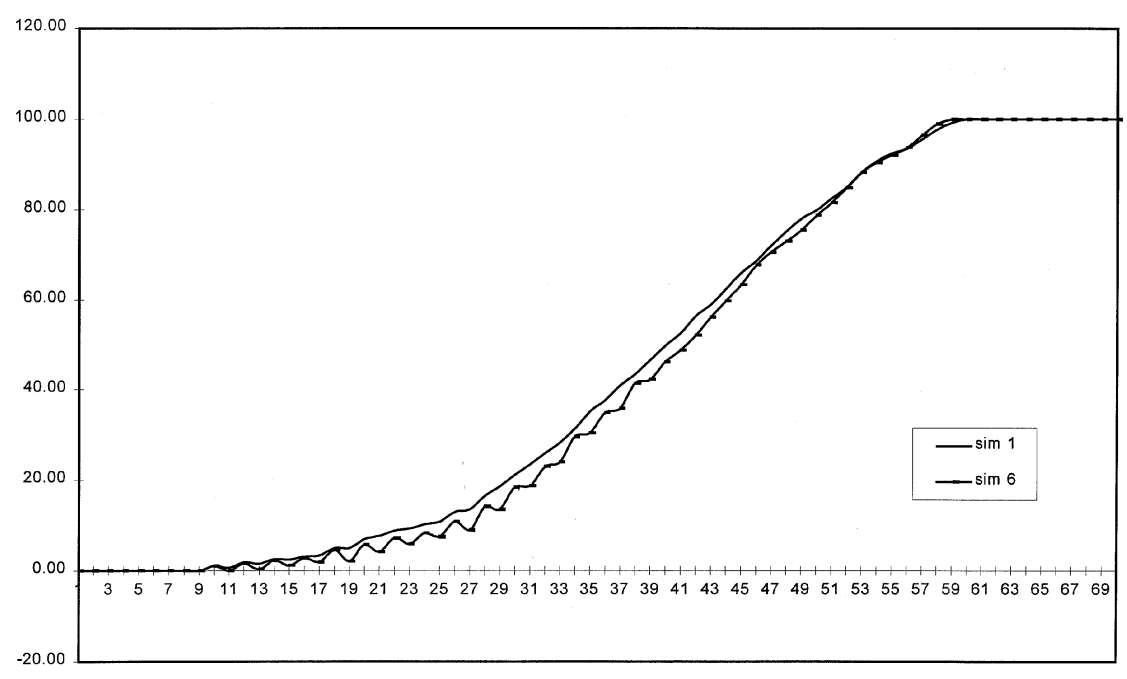

Figure 13. Aggregate diffusion in simulations 1 and 6.

dispersions. The indexes of dispersion of the stock reach values close to each other (but at different periods) in the first three sectors and are lower in sectors 4 and 5. Indeed, in sectors 1,2 and 3 , there is a period during which four different generations of equipment are simultaneously used, whereas in sectors 4 and 5, at worst, the stock is shared between three and two generations respectively. The technological distance is maximum in sectors 3, 4 and 5 which go through a period during which the old paradigm and the most modern generation of the new paradigm coexist in the stock of capital. In the other sectors ( 1 and 2), when generation 5 becomes available, the equipment of the old paradigm have already been entirely replaced. Sector 3 cumulates maximum dispersion and technological distances, and that is why its heterogeneity coefficient is superior to that of others.

The evolution of macroeconomic productivity goes through breaks (falls of the productivity levels) each time one generation of the new paradigm appears and makes it possible to use the application in an additional sector. On the one hand, the adoption of the new generation of technology leads to a fall of the productivity; and on the other hand, whereas in simulation 1 the slowing down of the productivity at the level of sector is decreasing with the date of adoption, in simulation 6 the heterogeneity leads to a break in productivity which is all the deeper as the adoption occurred late. Indeed, when one sector adopted the new technology for the first time, the technological distance between the oldest generation and the most modern generation of the stock is all the bigger as the adoption occurred late.

The heterogeneity of the capital delays by only three periods the catching up of the productivity level of the steady state. The pace of diffusion of the new technology at the macroeconomic level, in simulation 6, is more fluctuating and slower in the first phase; then it is stabilised and meets the pace of diffusion as in simulation 1, and actually passes it in the last periods (Fig. 13). This catching up can be explained by the fact that replace- 
ment is made faster when heterogeneity hinders productivity. Indeed, when the decision to invest is taken, the coefficient of heterogeneity marks the productivity of the vintage to be replaced, as well as that of the equipment likely to replace it. This tends to accelerate the replacement - in comparison to simulation 1 - since the effective productivity of the vintage of the new technology (heterogeneity coefficient being taken into account) meets the effective productivity of the vintage to be replaced more rapidly.

As a consequence, the third sector which has the highest coefficient of heterogeneity is the one whose diffusion accelerates the quickest, compared to simulation 1. If the heterogeneity disadvantages at first the diffusion of the new technology, it encourages the firm to replace the equipment more quickly and accelerates the end of the diffusion process.

\section{Conclusion}

Our diffusion model reproduces the productivity paradox, that is to say the slowing down of productivity gains following the introduction of a radically new technology in the economy. A positive technological shock does not translate immediately into productivity gains at the macroeconomic level. The diffusion and the efficient utilisation of a new technology can take time; a process of experimentation is necessary to obtain benefits associated to the adoption.

On the one hand, the technological improvements and the drop in acquisition costs only allow a progressive extension of application possibilities. On the other hand, the diffusion of technologies is a process marked by positive feedback; any obstacle to the diffusion also hinders the pace of learning which, in turn, slows down the process of diffusion. A low rate of the diffusion of knowledge among the sectors of economy slows the diffusion down. In a similar way, the heterogeneity of the stock of capital and the problems of technological compatibility resulting from it, makes the full potential of a new technology more difficult to obtain.

In our model, superposing the two paradigms and the different generations of the new paradigm tends to slow down the initial phase of diffusion. Yet, it encourages a quick replacement of the equipment. From this point of view, the model possibly reproduces the behaviour of many firms. However, we supposed that the firms are not limited in their financial possibilities. And the drop in the efficiency which follows the adoption of the new technology has a negative effect on the financial capacities of investments. It will be interesting, in future, to study more thoroughly the effects of financial constraints on the diffusion and the dynamics of productivity gains.

Acknowledgments. I am very grateful to Giovanni Dosi and Francesca Chiaromonte for their help and comments and to Nicolas Jonard and Marco Valento who programmed the model. 


\section{References}

Bresnahan T., Trajtenberg M. (1992) General purpose technologies: engines of growth?, CEPR discussion paper, No 300, July.

Brynjolfsson E. (1995) The productivity paradox of information technology: review and assessment, Economic Innovation and New Technologies 13, pp. 183-199.

Chiaromonte F., Dosi G. (1992) Les microfondements de la compétitivité et leurs conséquences macro-économiques. In : Foray D., Freeman C. (Eds), Technologie et Richesse des Nations. Economica, Paris, pp. 109-134.

David P. (1991) Computer and dynamo: the modern productivity paradox in a not-too-distant mirror. In: Technology and productivity. OCDE, Paris, pp. 315-348.

Dosi G., Freeman C., Nelson R., Silverberg G., Soete L. (1988) Technical change and economic theory. Pinter Publishers, London.

Freeman C., Perez C. (1988) Structural crisis of adjustment, business cycles and investment behavior. In: Dosi G., Freeman C., Nelson R., Silverberg G., Soete L. (Eds), Technical change and economic theory. Pinter Publishers, London, pp. 38-66.

Helpman E. Trajtenberg M. (1994) A time to sow and a time to reap: growth based on general purpose technologies, NBER Working Paper No. 4854.

Nelson R., Winter S. (1982) An evolutionary theory of economic change. Harvard University Press, New York.

Paillard S. (1998) Le paradoxe de la productivité et la diffusion des technologies de l'information. PhD Thesis, University of Paris I.

Rosenberg N. (1972) Factors affecting the diffusion of technology, Explorations in Economic History 10, pp. 3-33.

Silverberg G., Dosi G., Orsenigo L. (1988) Innovation, diversity and diffusion: a self-organisation model, Economic Journal 90, pp. 1032-1054.

to access this journal online: www.edpsciences.org 